\title{
Out of the ashes
}

\section{The Icelandic eruption has given researchers the opportunity of a lifetime. Katharine Sanderson talks to scientists working around the clock to study the volcano and its effects.}

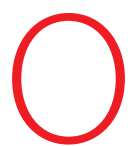

$\mathrm{n}$ the evening of 14 April, Gelsomina Pappalardo sent a rushed message to her colleagues across Europe, asking them to switch on their lasers and point them skywards. The volcano Eyjafjallajökull in Iceland had just erupted, and an unusual wind pattern was sending the ash cloud into Europe's crowded airspace. Pappalardo, who works at the Institute of Methodologies for Environmental Analysis outside Potenza, Italy, wanted to use the network of laser-based instruments, known as lidars, to measure the ash as it spread over the continent. It would be a chance for the lidar collaboration to shine.

Pappalardo, who coordinates the European Aerosol Research Lidar Network (EARLINET), wasn't the only scientist on high alert. As Eyjafjallajökull sullied the skies, dozens of researchers across Europe started scrambling to gather data. Atmospheric modellers, remote-sensing researchers, air-sampling experts, geologists and volcanologists are all taking advantage of this rare opportunity to measure a volcano in their own backyard.

Researchers in Iceland are probing the volcano's plumbing beneath the surface, whereas scientists farther afield are trying to assess the evolution of the ash cloud. All are hoping to fulfil their own scientific curiosity about a rare and dramatic phenomenon, but they must first answer to national governments and civil-aviation authorities, who are demanding data on the eruption as soon as possible to forecast potential problems. That means putting aside normal practices. Working virtually non-stop since the eruption, researchers are quickly gathering data and releasing them, instead of keeping the information to themselves until it is ready for publication.

"It's hard work for us," says Pappalardo, who has relied on the goodwill of her team to put in the extra hours for free to address government requests. "Since the 15 th of April, I've been sleeping two or three hours a night, maximum."

Pappalardo is faced with a problem: her data are highly valued by aviation authorities and atmospheric modellers, who want them instantly. But the measurements are not useful until they are analysed, and that takes time. The data are normally used in long-term studies of clouds, Saharan dust and other atmospheric components that affect the climate.

"This is not a simple technique," she says. Pappalardo wants to ensure that the information she gives to others is accurate, so that forecasts made with those data are correct. So she stays up late, collating and analysing data from the 26 lidar stations across Europe, and then making the results available to aviation authorities. In the future, she says she would like governments to support the infrastructure for real-time monitoring and automated analysis. Faster access to such data would help atmospheric modellers improve their projections of ash concentrations at various altitudes. Aviation officials need that information when deciding whether to close airspaces (see Nature 464, 1253; 2010).

\section{An eye on Eyjafjallajökull}

Icelandic scientists are at the centre of the action and have been the busiest of all. For them, Eyjafjallajökull is more than just a recent air-traffic nuisance. "I've been keeping a close watch on this volcano for 18 years," says Freysteinn Sigmundsson, a volcanologist from the Institute of Earth Sciences at the University of Iceland in Reykjavík, who is interested in how Earth's crust deforms during seismic events.

The volcano has been seismically jumpy for the entire time that Sigmundsson has studied it. But the earthquake activity intensified in December 2009, and came to a head with a lava-spewing eruption on the volcano's flank on 20 March. The spike in seismic unrest led authorities to evacuate people from the

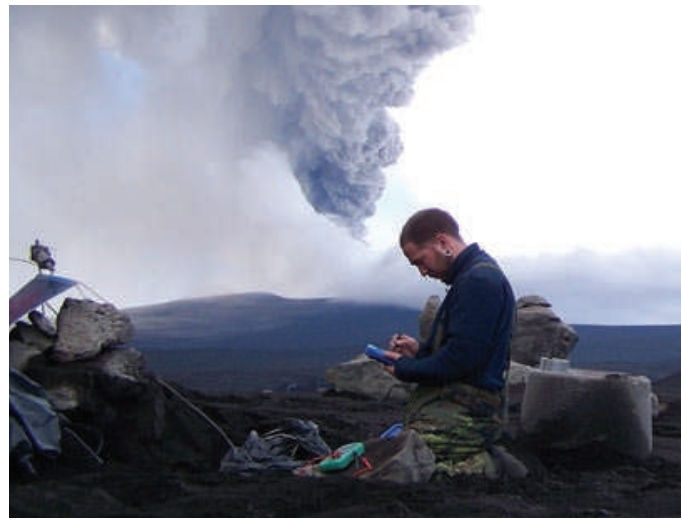

A researcher checks a seismic recorder near the volcano.
The Eyjafjallajökull eruption captured by scientists during an observation flight on 17 April.

volcano's immediate vicinity before its summit started shooting ash on 14 April.

This eruption seems to be similar to the volcano's previous one in 1821, which pulsed on and off for more than a year. Although the nineteenth-century pattern might indicate that the present eruption will be prolonged, the magmatic plumbing under Eyjafjallajökull is complicated says Sigmundsson, making predictions difficult. "There is no way of knowing how long this will last," he says.

Sigmundsson and his colleagues want to trace the magma conduits that feed the volcano. To do this, they track ground movement using Global Positioning System receivers around Iceland and satellite-borne radar interferometers, while seismic recordings provide information about underground structures. Such data are useful for the Icelandic Meteorological Office and the government, which must assess whether the volcanic activity is likely to increase.

Magnús Tumi Gudmundsson, head of the faculty of Earth sciences at the University of Iceland, is watching the eruption itself using a variety of means, including radar instruments that can see through the ash cloud into the crater. His research group is studying the composition and amount of ash and rock discharged from the volcano, as well as water generated from the melting of glacial ice on top of Eyjafjallajökull. These 


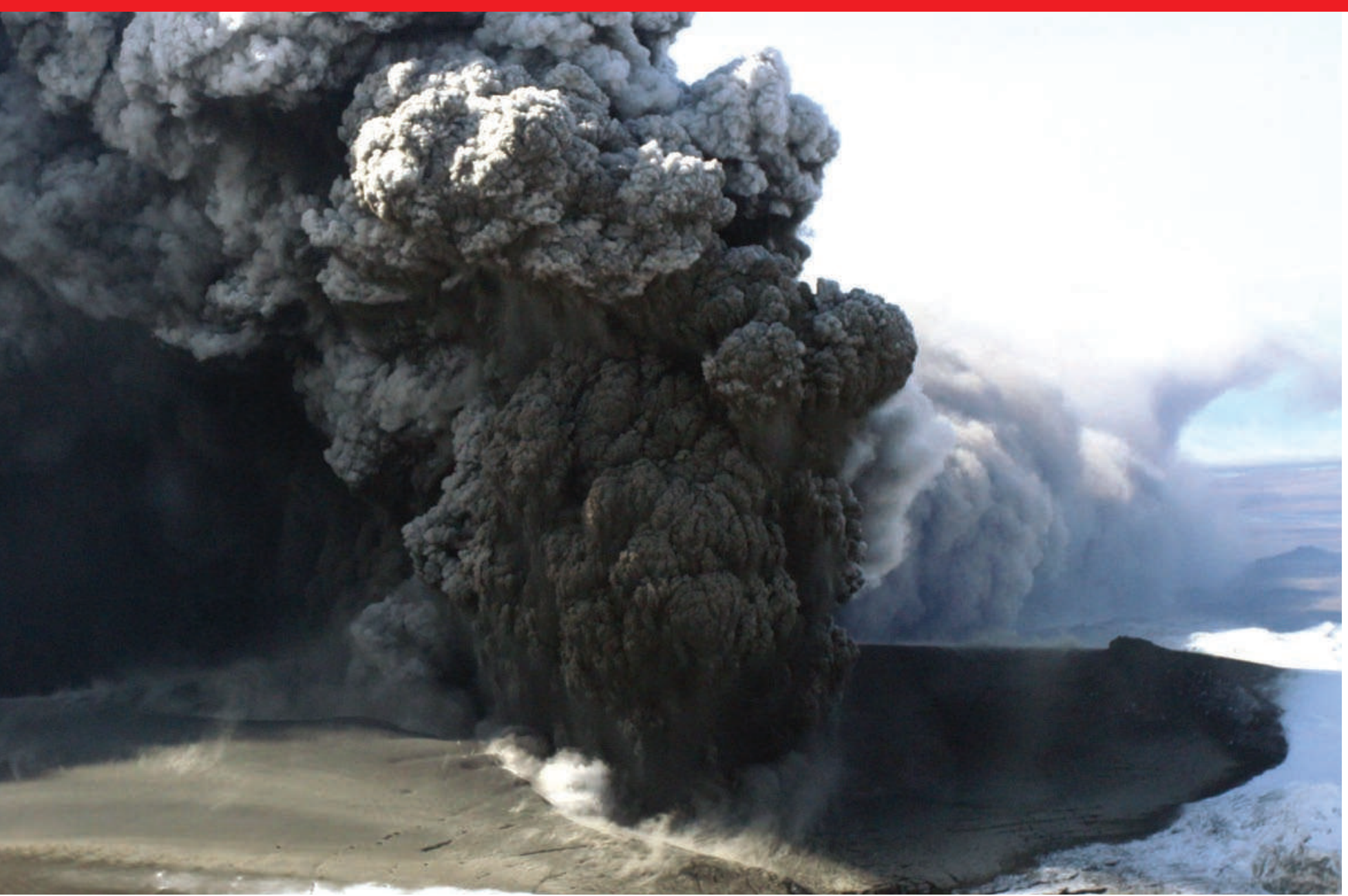

data can help to predict whether the volcano will produce ash or lava, as well as whether floods are likely.

\section{Fire and water}

The meltwater produced by the initial stages of the eruption had far-reaching consequences. Researchers suspect that the interaction between water and magma produced exceptionally fine-grained ash. Between $50 \%$ and $70 \%$ of the ash grains were less than 100 micrometres in diameter, and some were smaller than 10 micrometres, says Gudmundsson. Such minute particles stay airborne longer than heavy particles, and they can get into jet engines and then melt, causing damage. Because the eruption quickly melted all ice near the summit, the ash grew coarser after the first four days.

As they gather their data, Gudmundsson and his colleagues upload much of it to the university's website and send it to the Icelandic Meteorological Office. Gudmundsson says that 20 people from his institute are working "flat out" to monitor the volcano - putting aside regular research projects to do so. Eventually, Gudmundsson hopes to make geological sense of the data, and use them to investigate the magma chambers beneath the volcano and what controls the changes in magma behaviour, particularly when it interacts with water. At the moment all ideas are "highly speculative", he

says. "I haven't had a chance to get a handle on changes that are happening."

While Pappalardo, Sigmundsson and Gudmunsson's teams rushed to measure the eruption, Urs Baltensperger just had to bide his time. Baltensperger runs an atmospheric chemistry lab at the Paul Scherrer Institute in Villigen, Switzerland, which has instruments atop Jungfraujoch, a 3,500-metre-high Swiss mountain. Once Baltensperger realized that the ash cloud was on its way, he knew that this was a datacollection opportunity too good to miss. "We just had nothing to do but sit back, relax and wait for the plume to arrive," he says.

Baltensperger's team, and his colleagues at Empa, the Swiss federal laboratories for materials science and technology, used filters and other instruments to determine the ash's mass concentration - the mass per volume of air. His group also measured how much light the

\section{"There is no way of knowing how long this will last."} ash cloud was blocking. From those two values, the researchers could calculate a parameter needed to turn lidar information into measures of how much ash is in the sky, of what type, and at what altitude. Such data complement the information provided to aviation authorities by Pappalardo's lidar network.

Baltensperger was happy to pass his results on to the Swiss aviation authority. But, like Pappalardo, he says that to monitor future eruptions properly, real-time analysis and an automated data-transmission system are required.

The eruption and the crisis it created in Europe are uniting researchers in unusual ways. Thor Thordarsson, a volcanologist from the University of Edinburgh, UK, who was in Iceland when the eruption began, says that because the ash blew over northern Europe, with its dense research network, it presents a unique opportunity to reconstruct the entire eruption and work out what happened within the volcano. But, as he told a group of UK-based scientists in Oxford at the end of April, "It can only work if everyone works together."

Sigmundsson has taken a strategic approach to the release of data. His group posts updates on the seismicity, meltwater and the nature of the plume, such as its height, colour and heading. But it doesn't put up raw information. "We are expecting other scientists to allow us time to fully analyse those data for scientific publications," he says.

Pappalardo says she hopes that her team's efforts to get lidar data out to the people who need them will bring something in return. The EARLINET lidar network has been running for a decade, at times on a completely voluntary basis. In a brief break from her work, she says the eruption might help to secure long-term funding for the network. "Now everybody wants to have these data."

Katharine Sanderson is a freelance writer in London. 